DOI 10.37882/2223-2974.2021.02.16

\title{
ПРЕКРАЩЕНИЕ ГРАЖДАНСКО-ПРАВОВЫХ ОБЯЗАТЕЛЬСТВ В ДОГОВОРНОМ ПОРЯДКЕ (В ГРАЖДАНСКИХ КОДЕКСАХ РОССИИ, ФРАНЦИИ И ГЕРМАНИИ)
}

\section{TERMINATION OF CIVIL OBLIGATIONS IN A CONTRACTUAL MANNER (IN THE CIVIL CODES OF RUSSIA, FRANCE AND GERMANY)}

\section{A. Repin}

Summary: The article is devoted to contractual methods of termination of civil obligations under Russian, German and French legislation. The author conducted a comparative legal analysis, identified the features of the application of the rules on compensation, novation, set-off, debt forgiveness, as well as the possibility of concluding an unnamed agreement in each of the countries and formulated conclusions about the distinctive and similar positions of legislators to contractual methods of termination of obligations.

Keywords: termination of obligations, novation, compensation, set-off, debt forgiveness, Russian law, German law, French law, contract.
Репин Артем Вадимович

Аспирант, Московский государственный юридический университет им. О.Е. Кутафина (МГЮА), г. Москва artem0595@mail.ru

Аннотация: Статья посвящена договорным способам прекращения гражданско-правовых обязательств по российскому, германскому и французскому законодательству. Автором проведен сравнительно-правовой анализ, выявлены особенности применения правил об отступном, новации, зачета, прощения долга, а также возможности заключения непоименованного соглашения в каждой из стран и сформулированы выводы об отличительных и схожих позициях законодателей к договорным способам прекращения обязательств.

Ключевые слова: прекращение обязательств, новация, отступное, зачет, прощение долга, российское право, германское право, французское право, договор.

На наш взгляд, особое внимание необходимо обратить именно на договорные способы прекращения обязательств, относящиеся к волевым способам, содержащихся в основных гражданских нормативно-правовых актах России, Франции и Германии.

Сравнение гражданских кодексов вышеуказанных стран обусловлено отнесением их к романо-германской правовой семье, что предполагает схожий подход к регулированию различных правовых институтов, в том числе, прекращения обязательств. Однако это не обязательно предполагает идентичный подход законодателя к различным институтам.

В первую очередь, обратимся к российскому гражданскому законодательству, содержащему нормы о прекращении обязательств.

В соответствии с положениями главы 26 Гражданского кодекса РФ (далее - ГК РФ) гражданско-правовые обязательства могут быть прекращены, в том числе, следующими способами: отступное, новация, прощение долга.

Вышеуказанные способы прекращения обязательств являются договорными, что предполагает заключение соглашения между субъектами правоотношения, направленного на утрату контрагентами права требования 
к управомоченному лицу и соответствующей этому праву обязанности.

Следует отметить, что перечень способов прекращения гражданско-правовых обязательств является открытым, что предполагает и существование иных договорных способов, кроме названных в главе 26 ГК РФ.

Так, наиболее интересным с практической точки зрения с учетом диспозитивности и автономии воли сторон является возможность заключения любого непоименованного в законе соглашения, целью которого является прекращение гражданско-правового обязательства. Согласно п. 3 ст. 407 ГК РФ, стороны своим соглашением вправе прекратить обязательство и определить последствия его прекращения, если иное не установлено законом или не вытекает из существа обязательства.

На наш взгляд, данная норма является важной для правоприменительной практики, так как субъектам гражданских правоотношений предоставляется право использовать не только предусмотренные ГК РФ договорные конструкции, направленные на прекращение обязательств, но и заключать непоименованные соглашения.

Возможность заключения такого непоименованного соглашения, позволяющего прекратить гражданскоправовое обязательство, все чаще становится предметом рассмотрения судебными инстанциями по причине развития оборота и частого использования этого инструмента субъектами гражданских правоотношений, а также отсутствием со стороны законодателя четких правил заключения таких соглашений в части формы и существенных условий. Также следует отметить, что Верховный суд РФ продолжает занимать позицию по поддержке превалирования воли сторон над формальными положениями законодательства, в том числе, и в части прекращения обязательств.

В частности, Верховный суд РФ в своем недавнем Постановлении Пленума от 11 июня 2020 г. № 6 «О некоторых вопросах применения положений Гражданского кодекса Российской Федерации о прекращении обязательств» (далее - Постановление Пленума № 6) указал, что перечень оснований прекращения обязательств не является закрытым, поэтому стороны могут в своем соглашении предусмотреть не упомянутое в законе или ином правовом акте основание прекращения обязательства и прекратить как договорное, так и внедоговорное обязательство, а также определить последствия его прекращения, если иное не установлено законом или не вытекает из существа обязательства (пункт 3 статьи 407 ГК РФ).

Более того, суд, указывая на большую значимость договоренностей сторон сделки, которая направлена на прекращение обязательств, допускает возможность применения зачета, как способа прекращения обязательств, предусматривающего заявление одной стороны по правилам, предусмотренным для заключения непоименованных соглашений в рамках пункта 3 статьи 407 ГК РФ.

Так, Верховный суд указал, что стороны вправе согласовать между собой порядок прекращения встречных взаимных требований в порядке, отличном от предусмотренного статьей 410 ГК РФ, например, автоматическое прекращение обязательства в отсутствие заявления одной из сторон в случае наступления какого-либо обстоятельства, либо невозможность прекращения обязательств посредством зачета односторонним волеизъявлением стороны, а только при достижении соглашения между всеми сторонами договора.

Для сравнения укажем, что зачет по Гражданскому кодексу Франции 1804 года, не требует каких-либо заявлений со стороны кредиторов или должников с целью его осуществления (ст. 1290 главы 5 титула III книги 3).

Указанное положение является спорным с точки зрения правоприменения. Положение о зачете, закрепленное в ГК РФ, и расширенное Верховным судом РФ В части возможности заключения соглашения, изменяющим порядок применения зачета, является более подходящим, так как представляется, что для прекращения обязательств, вне зависимости от выбранного способа, необходимо согласование воли всех сторон правоотношения.

Также возможность прекращения обязательств путем заключения соглашения закреплено и в других положениях ГК РФ. Так, к таким положениям имеет смысл отнести п. 6 ст. 450.1 ГК РФ, согласно которому, сторона сделки может отказаться от осуществления какого-либо своего права в правоотношениях с контрагентом. Например, соглашением между поставщиком и покупателем по расторгнутому договору поставки может быть предусмотрен отказ последнего от взыскания возможных убытков, связанных с наступлением определенных обстоятельств, что не позволит ему обратиться с исковыми требованиями в суд с таким предметом.

Для сравнения проведем анализ норм о прекращении обязательств, закрепленных в Гражданском кодексе Франции 1804 года.

Способы прекращения гражданско-правовых обязательств перечислены в ст. 1234 главы 5 титула III книги 3 Кодекса Наполеона. Согласно вышеуказанной статье, способами прекращения обязательств являются: платеж; новация; добровольный отказ кредитора от своих прав; зачет; уничтожение вещи; ничтожность обязатель- 
ства; действие отменительного условия и давность действия конкретного обязательства.

Следует обратить внимание на то, что Кодекс Наполеона, в отличие от ГК РФ, не содержит положений о возможности заключения соглашений, прямо не предусмотренных законом - непоименованных договоров, направленных на прекращение гражданско-правовых обязательств. Однако из смысла некоторых норм такая возможность следует.

Кодекс Наполеона относит к поименованным договорным способам прекращения обязательств - новацию и отступное.

Согласно ст.1271 Кодекса Наполеона новация может быть совершена по трем основаниям:

1. когда должник, по отношению к своему кредитору, принимает на себя новый долг, который ставится на место прежнего;

2. когда новый должник заступает место прежнего, который, в то же время, освобождается кредитором от обязательства;

3. когда в силу нового соглашения, новый кредитор становится на место прежнего, по отношению к которому должник освобождается от обязательства.

Кодекс Наполеона в конструкцию новации включает правила о перемене лиц в обязательствах, приравнивая уступку права требования и перевод долга к замене первоначального обязательства.

Представляется, что перемена лиц не является способом прекращения обязательства, так как замена кредитора или должника не влияет на сохранение обязанности по совершению того или иного действия управомоченным лицом.

Следует согласиться с позицией В.И. Синайского, что новация может иметь место только между сторонами первоначального обязательства, иначе утрачивается правовая природа новых правоотношений - первоначальное обязательство является прекращенным.

Также относительно участия третьих лиц в обязательствах, которые прекращаются новацией, Подгорбунская Н.О. считает, что изменение участника правоотношения при новации третьим лицом не допускается, так как по правилам, установленным в ст. 414 ГК РФ, для действия новации должна сохраняться правосубъектность у должника и кредитора именно по первоначальному обязательству.

В отличие от ГК РФ, положения Кодекса Наполеона о новации содержат условия, при которых соглашение о замене (по Кодексу Наполеона - обновлении) обязатель- ства будет действительным.

Согласно ст. 1272 Кодекса Наполеона, обновление может совершаться только между лицами, способными вступать в договоры. В ст. 414 ГК РФ не закреплено специальное правило о дееспособности сторон соглашения о новации. Данное условие предполагается, исходя из общих положений о действительности сделок. В соответствии с п. 1 ст. 171 ГК РФ ничтожна сделка, совершенная гражданином, признанным недееспособным вследствие психического расстройства.

На наш взгляд, специально указанное положение о дееспособности, закрепленное в ст. 1272 Кодекса Наполеона, необходимо в связи с таким основанием для совершения новации, как перемена лиц в обязательстве.

Следует отметить, что положения Кодекса Наполеона о новации предусматривают необходимость указывать в соглашении о новации на намерение замены первоначального обязательства.

Ст. 1273 Кодекса Наполеона установлено, что замена первоначального обязательства не предполагается; требуется, чтобы намерение совершить его ясно вытекало из волеизъявления сторон. ГК РФ подобного положения не содержит. Утверждение «новация не предполагается» был только в п. 2 Информационного письма Президиума ВАС РФ от 25 декабря 2005 г. № 103.

В Постановлении Пленума № 6 так же указано, что воля сторон на применение правил о новации должна быть четко определена. При наличии у суда сомнений относительно применения правил о новации или отступном, необходимо применять правила об отступном. По нашему мнению, такое положение является необходимым для указания в статье 414 ГК РФ, так как существуют судебные споры, где соглашение, заключенное между сторонами, не было признано новацией в связи с отсутствием указания на применение к такому соглашению соответствующих положений.

О необходимости прямого указания в соглашении между сторонами первоначального обязательства на применение правил о новации также указывают и современные российские ученые. Так, например, Эрделевский А.М. считает, что правомерно судить о несостоятельности соглашения о новации в случае отсутствия указания сторонами на применение правил ст. 414 ГК РФ, так как любое соглашение, устанавливающее обязательство, необходимо рассматривать индивидуально и отсутствие указания на правила о новации в новом обязательстве, может изменить природу такого соглашения.

Согласно п. 2 статьи 414 ГК РФ, новация прекращает дополнительные обязательства, связанные с первона- 
чальным обязательством, если иное не предусмотрено соглашением сторон.

Прекращение новацией дополнительных обязательств, связанных с первоначальным, закреплены в Кодексе Наполеона в ст. ст. 1278, 1280-1281.

Интерес представляет положение ст. 1281 об участии солидарных должников и поручителей в новом обязательстве: «если кредитор требовал, в первом случае, участия содолжников, или, во втором, участия поручителей, то прежний долг не уничтожается, если содолжники или поручители отказались принять участие в новом соглашении». Таким образом, в данной статье закреплено правило о незаключенности соглашения о новации в случае, если солидарные должники и (или) поручители отказались от заключения соглашения о новации.

Представляется, что в связи с узким содержанием нормы, регулирующей правила о новации в гражданском законодательстве РФ (414 ГК РФ), а также отсутствием отдельных положений, предусматривающих требования к соглашению о новации, а также его действительности, имеет смысл добавить схожее положение, закрепленное в ст. 1281 Кодекса Наполеона об одобрении прекращения обязательства путем замены первоначального со стороны поручителей или содолжников.

Новацию, как способ прекращения обязательств, признают немецкие ученые и обосновывают в литературе по обязательственному праву Германии в отсутствие на прямое указание на такой способ прекращения обязательств в Германском Гражданском уложении (далее - ГГУ). Так, по мнению немецких правоведов, возможность соглашением сторон заменить первоначальное обязательство на новое (Schuldersetzung) закреплена в принципе свободы договора, указанный в параграфе 311 Раздела 2 Книги 2 ГГУ. Также в науке немецкого права новацию сравнивают с соглашением об изменении условий (Änderungsvertrag), согласно которому стороны вправе изменить предмет и условия первоначального обязательства. Однако, следует отметить, что согласно параграфу 364 Раздела 2 Книги 2 ГГУ, при наличии сомнения возникновение нового обязательства не предполагает замену первоначального обязательства, а рассматривается как дополнительное. Следовательно, возникновение нового обязательства не обязательно предполагает прекращение первоначального новацией.

Вместе с тем, ГК РФ и Кодекс Наполеона, так же, как и ГГУ, рассматривают базисом заключения любого соглашения, в том числе, и новации принцип свободы договора, который отражает превалирование автономии воли и диспозитивности участников гражданских правоотношений в романо-германской правовой системе.
Рассматривая нормы, регулирующие соглашение о новации, предусмотренные в ГК РФ, Кодексе Наполеона и ГГУ, необходимо отметить, что ни в одном из перечисленных нормативно-правовых актах не предусмотрены правила о форме, в которой должно быть заключено соглашение о замене первоначального обязательства на новое.

Российские ученые отстаивают мнение, что так как соглашение о новации, в первую очередь, направлено на прекращение гражданско-правового обязательства, то оно должно совершаться в форме первоначального. К примеру, Андреев Ю.Н. прямо указывает на то, что в случае прекращения обязательства, заключенного в нотариальной форме, соглашение о новации должно следовать форме первоначального.

На наш взгляд, указанная точка зрения является обоснованной, так как действительность нового обязательства, возникающего на основании соглашения о новации, должно подчиняться тем же нормам законодательства, которыми руководствовались стороны первоначального обязательства. Указанное утверждение подтверждается законодателем в пункте 1 статьи 452 ГК РФ, согласно которому соглашение об изменении или о расторжении договора совершается в той же форме, что и договор, если из закона, иных правовых актов, договора или обычаев не вытекает иное.

Исходя из вышеизложенного, представляется целесообразным дополнить положения ст. 414 ГК РФ условием о форме соглашения о новации, с целью предотвращения спорных ситуаций, связанных с действительностью такого соглашения.

Следующим рассматриваемым договорным способом прекращения обязательств является отступное. В ГК РФ отступное, как договорный способ прекращения обязательств, закреплено в ст. 409, согласно которой, по соглашению сторон обязательство может быть прекращено предоставлением отступного - уплатой денежных средств или передачей иного имущества.

По мнению Садиковой О.Н., отступное является способом прекращения обязательства, при котором стороны вправе прекратить такое обязательство путем замены предмета его исполнения на другой. В настоящее время положение об отступном, как о способе прекращения обязательств, закреплено в ст. 1243 Кодекса Наполеона. Согласно данной статье, кредитор не может быть принуждаем принять в уплату, вместо следующей ему вещи, другую, хотя бы ценность предлагаемой вещи была равная или даже высшая. Исходя из принципа свободы договора, закрепленного в ст. 1134 Кодекса Наполеона, стороны могут заключить соглашение о передаче имущества в счет погашения долга. 
Ранее Кодексом Наполеона было предусмотрено заключение соглашения об отступном. Исходя из отмененных положений ст. ст. 1265-1270 («Об уступке имущества»), предусматривались судебная и добровольная уступка имущества. Добровольная - это такая уступка, которую кредиторы принимают добровольно, и которая не имеет никаких других последствий, кроме тех, которые вытекают из условий договора, заключенного между ними и должником. Видится, что отмена специального регулирования соглашения об отступном связано с действием принципа свободы договора и отказом от формального подхода к закону, которые являются основой диспозитивного метода правового регулирования в романо-германской правовой семье.

Согласно параграфу 364 Раздела 3 Книги 2 ГГУ, обязательство прекращается в случае, если кредитор принимает взамен исполнения не то удовлетворение, которое ему следовало (Erfüllungssurrogate). На наш взгляд, исходя из положения вышеуказанного параграфа, является необходимым заключение соглашения между сторонами обязательства о замене предмета его исполнения. Однако, в немецкой правовой науке мнения ученых разделились относительно квалификации соглашения об отступном и его зависимости от первоначального обязательства. Согласно первой точке зрения, для действительности отступного между сторонами необходимо заключение возмездного договора, предусматривающего обмен обязательствами (entgeltliche Austauschvertrag), направленный на освобождение от первоначального обязательства и возникновение нового встречного обязательства. Согласно второй точке зрения, сторонам необходимо лишь заключить дополнительное соглашение, изменяющее условия первоначального обязательства (Änderungsvertrag). В настоящее время превалирует позиция, согласно которой договоренность ограничивается лишь оговоркой, согласно которой выполненное действие следует считать исполнением (Erfüllungsvertrag). Указанная позиция отражает подход, при котором первоначальное обязательство, вне зависимости от заключенного соглашения об отсупном, является основой для принятия исполнения с управомоченной стороны. Согласно сложившейся российской судебной практике, с момента заключения соглашения об отступном у должника возникает право на замену предмета исполнения и требовать от кредитора его принять. В случае, если должником не будет исполнена обязанность по передаче отступного в порядке, указанным в соглашении, кредитор вправе требовать возврата к условиям исполнения первоначального обязательства.

На наш взгляд, в случае заключения сторонами обязательства соглашения об отступном, первоначальное обязательство становится факультативным.

По мнению Витрянского В.В., при таком подходе, иг- норируются права и законные интересы кредитора, которому предлагается повторно довериться должнику, однажды уже допустившего нарушение первоначального обязательства. Исходя из вышеизложенного, нормы об отступном, содержащиеся в ГК РФ, Кодексе Наполеона и ГГУ, являются схожими между собой, а именно в части природы такого способа прекращения обязательства, а также его формы и способа исполнения. Подход немецкого права относительно непосредственной зависимости обязательства об отступном от первоначального обязательства совпадает с указанными в ГК РФ и Кодексе Наполеона позициями. Однако, следует обратить внимание, что нормы об отступном ни в одном из кодексов не являются всеобъемлющими, и одновременно основываются на судебной практике, мнениях ученых и основных началах гражданского законодательства, что является не совсем достаточным для современного гражданскоправового оборота.

Одним из распространенных способов прекращения обязательства является прощение долга. Согласно п. 1 ст. 415 ГК РФ, обязательство прекращается освобождением кредитором должника от лежащих на нем обязанностей, если это не нарушает прав других лиц в отношении имущества кредитора. Особенностью данного способа прекращения обязательства является то, что он не предполагает предоставления какого-либо встречного предоставления со стороны должника кредитору. В связи с указанным, прощение долга связано с конструкцией дарения, закрепленная в п. 1 ст. 572 ГК РФ, согласно которому по договору дарения одна сторона (даритель) безвозмездно обязуется передать другой стороне (одаряемому) вещь в собственность либо имущественное право (требование) к себе или к третьему лицу либо освобождает или обязуется освободить ее от имущественной обязанности перед собой или перед третьим лицом. Витрянский В.В. придерживается точки зрения о том, что прощение долга является двусторонней сделкой между кредитором и должником, обосновывая тем, что кредитор обязан направить уведомление, и только в случае отсутствия в разумный срок возражений должника, обязательство будет считаться прекращенным. Следовательно согласие должника на прощение долга может быть выражено конклюдентными действиями должника. Также профессор Витрянский В.В. указывает, что чаще всего на практике прощение долга оформляется двусторонним соглашением сторон.

На наш взгляд, прощение долга, как и любой способ прекращения обязательства, может быть применен только после согласования воли сторон прекращаемого обязательства, основываясь на принципах добросовестности и свободы договора. Одностороннее прекращение обязательства лишает другую сторону на использование собственных ресурсов для погашения обязанности перед контрагентом. Кодексом Наполеона предусмотрено 
положение о прощении долга - сложение долга, закрепленное в ст. 1234 и разделе 3 главы 5 Титула 3.

Однако, при рассмотрении положений Кодекса Наполеона о сложении долга, в нем отсутствуют условия о форме и основании освобождения должника от обязательства. В сравнении с Кодексом Наполеона положения ГК РФ о прощении долга содержат полное освобождение должника от лежащих на нем обязанностей без специального указания на солидарных должников и поручителей, что представляется более верным с практической точки зрения.

В параграфе 397 Раздела 3 Книги 2 ГГУ закреплено положение о прощении долга, именуемое как освобождение от исполнения. В отличие от ГК РФ освобождение от исполнения может быть осуществлено только посредством заключения соглашения между должником и кредитором, предметом которого будет являться прекращение обязательства (Verfügungsvertrag). Согласно широко применяемому в немецком правовой доктрине принципу свободы договора соглашение об освобождении исполнения может быть составлено сторонами в свободной форме. Данное условие действует также в случаях, когда основанием прощения долга является дарение. С момента заключения такого соглашения обязанная сторона считается исполнившей свои обязательства перед кредитором, а обязательственные отношения считаются прекращенными. Элементы прощения долга могут содержаться в договоре о прекращении обязательств (Aufhebungsvertrag), являющееся аналогом соглашения о прекращении обязательств, закрепленное в п. 3 ст. 407 ГК РФ. Однако, в ГГУ прямо не указана возможность заключения такого соглашения и, следовательно, участники гражданско-правового оборота вправе руководствоваться общими началами гражданского законодательства, применяя принцип свободы договора с целью прекращения обязательств по согласию сторон с использованием различных конструкций и способов прекращения.

В заключении необходимо отметить, что Гражданский кодекс РФ, Кодекс Наполеона и Германское Гражданское Уложение, содержат схожие договорные способы прекращения обязательств, однако, при сравнении правовых норм и условий их применения, наблюдаются различия, влияющие на возможность их применения участниками гражданско-правового оборота. Так, например, в отличие от ГК РФ и Кодекса Наполеона, ГГУ прямо не указывает на наличие важного способа прекращения обязательств как новация. В Кодексе Наполеона, в свою очередь, не закреплен такой способ прекращения обязательств как непоименованное соглашение.

\section{ЛИТЕРАТУРА}

1. Андреев Ю.Н. Новация как способ прекращения обязательства // Право и государство: теория и практика. - 2006. - № 10. - С. 43 - 54.

2. Витрянский В.В. Реформа российского гражданского законодательства: промежуточные итоги. М.: Статут. - 2018. - С. 363.

3. Гражданский кодекс Франции (Кодекс Наполеона) от 21.03.1804 г. (с изм. и доп. по состоянию на 01.09.2011 г.)

4. Информационное письмо Президиума ВАС РФ от 21.12.2005 г. № 102 «0бзор практики применения арбитражными судами статьи 409 Гражданского кодекса РФ». «Вестник ВАС РФ». - 2006. - № 4 (06зор).

5. Иоффе 0.С. Обязательственное право. М.: Юридическая литература. - 1975. - С. 96.

6. Лоошелдерс Д. Обязательственное право: общая часть. Мюнхен: издательство Франц Фален. - 2014. - С. 158-161.

7. Лоошелдерс Д. Обязательственное право: общая часть. Мюнхен: издательство Франц Фален. - 2014. - С. 143 - 144.

8. Медикус Л. Обязательственное право: Общая часть. Мюнхен: 19-е изд., издательство С.Н. Beck. - 2010. - С. 145.

9. Мюнхенский комментарий к Германскому гражданскому уложению: научно-практический комментарий под ред. Фетцера

10. Подгорбунская Н.О. Правовая природа новации как способа прекращения обязательств // Вестник КемГУ. Серия: Гуманитарные и общественные науки. - 2018. - № 2. - С. $93-97$.

11. Постановление Пленума Верховного суда РФ от 11 июня 2020 г. № 6 «0 некоторых вопросах применения положений Гражданского кодекса Российской Федерации о прекращении обязательств» - «Российская газета». - 2020. № - 136.

12. Садикова 0.Н. Комментарий к Гражданскому кодексу, части первой. М.: Контракт. - 2005. - С. 135.

13. Синайский В.И. Русское гражданское право. М.: Статут. - 2002. - С. 747.

14. Соломин С.К. Понятие прекращения обязательства // Вестник Томского государственного университета. Право. - 2014. - № 2 (12). - С. 117 - 121.

15. Эрделевский А. М. 0 прекращении обязательств новацией // Законодательство. - 2008. - № 1. - С. 31 - 34. 